\title{
Uniform Output Subsidies in Economic Unions versus Profit-shifting Export Subsidies
}

\author{
Bernardo Moreno \\ University of Málaga \\ and \\ José L. Torres \\ University of Málaga
}

\begin{abstract}
This paper focuses on the effect of output subsidies in an economic union in the context of a thirdmarket model where there are two countries which produce a homogeneous good consumed in a third country. We study the importance of cost asymmetry between firms in different countries, and the elasticity of demand in the case of countries that join an economic union with harmonized output subsidies. We find that the optimal level of subsidy in the economic union can be negative (a tax) if firms have different costs and the demand is concave. We also compare the optimal subsidy in the economic union with the pre-union export subsidies with the result that the new policy generally favours the less efficient countries.
\end{abstract}

\section{JEL Classifications: F13}

Key Words: Output Subsidies, Economic Union

\footnotetext{
*Corresponding address: Bernardo Moreno, José L. Torres, Department of Economics, University of Málaga, El Ejido s/n, 29013 Malaga, Spain, Tel: +00-34-952131247, Fax: +00-34-952131299, Email: bernardo@uma.es, jtorres@uma.es
} 


\section{Introduction}

The European Union has attempted to harmonise all aid being given by the governments of member states to the different industrial sectors. This was done to eliminate or reduce distortion of competition within the Community. In this paper we analyse the effects of uniform production subsidies in an economic union of two producing countries and a third consuming country, in an imperfectly competitive market, using Brander and Spencer's [1985] so-called third-market model. ${ }^{1}$ The aim of the paper is to compare the previous pre-union situation, in which each government, independently and simultaneously sets a profit-shifting export subsidy to its firm, with a situation in which the three countries form an economic union with similar subsidies for the two producing countries.

Following Balassa [1961], we can distinguish several stages or levels of economic integration among countries, such as free trade areas, customs unions, common markets and monetary unions. ${ }^{2}$ In this paper, we define an economic union as an area with a common economic authority which decides the same level of output subsidies for all the firms in an oligopolistic industry.

First, we study the traditional problem in terms of the optimal subsidy level, in a pre-union step. In the pre-union case, we obtain the conventional result that the lower cost firm obtains the highest subsidy, as shown by Neary [1994] and De Meza [1986]. Brander and Spencer [1985] were the first to show that, in a Cournot duopoly setting, an export subsidy to a home firm is desirable because it raises the firm's market share and profits at the expense of its foreign competitor. Neary [1994] considers the problem in which the social cost of public funds exceeds unity, following Gruenspecht [1988]. He finds that subsidies are optimal only for surprisingly low values of the social cost of public funds and, if subsidies are justified, they should be higher the more cost competitive the domestic firms are. However, as is pointed out by Bandyopadhyay [1997], this result is reversed in the presence of inelastic demand. For an excellent survey about strategic trade policy and the different extensions of the third-market model see Brander [1995].

Following Brander and Spencer [1985], we consider the existence of three countries. We depart from the traditional case and weigh the existence of an economic union. Countries (firms) 1 and 2 produce a homogeneous good in an imperfectly competitive market. There is no consumption

\footnotetext{
${ }^{1}$ Following Brander [1995] a third-market model can be defined as one in which firms from a domestic country and firms from a foreign country only compete in a third market, in other words, they only produce to export. This simplification turns out to be very useful in allowing the strategic effects of export subsidies to be seen in pure form and this is the reason why this model has been extensively used in the literature.

${ }^{2}$ See Hine [1994] for a survey on the international economic integration literature.
} 
in the producing countries. Country 3 imports the imperfectly competitive good. We explore the case in which the three countries join an economic union with a common economic authority. Therefore, in this case, the common economic authority chooses the same level of subsidies for the two firms, in terms of welfare maximization in the economic union.

We assume that the objective of the common economic authority is to maximize social welfare in the union, taking both producers and consumers into account. We find that the optimal output subsidy level can be negative (a tax) if the demand is concave when firms have different cost. As a result, in the case of a linear demand and symmetry in costs, the optimal level of subsidy in the economic union yields a competitive market level of output.

Comparing the economic union with the export subsidies case in the standard third-market model, the effects of the new policy depend on the relationship between the new uniform subsidy level and the previous profit-shifting export subsidy levels settled by each country. We find that in the case of a linear demand, the optimal subsidy in the economic union is larger than the optimal subsidies in the pre-union export subsidies case. We also find that, in the symmetric cost case, the optimal subsidy level in the economic union is larger than in the non-cooperative pre-union export subsidies situation, independently of the curvature of the demand function. In order to compare both cases with asymmetries in costs, we consider the two special cases, when the optimal subsidy in the economic union is equal to the optimal subsidy for each firm in the pre-union noncooperative export subsidy case. In both cases, the result is that the new policy favours the less efficient firm.

The structure of the paper is as follows. Section II presents the model and analyses the standard case of two exporting countries, each using export subsidies to improve the relative position of its firm. In Section III, we derive the optimal subsidy level in an economic union formed by the two exporting countries and the importing country with a common economic authority that chooses the same level of subsidies for the two firms. We compare the results with the profit-shifting export subsidies pre-union situation. Section IV concludes the paper.

\section{The model}

Following Brander and Spencer [1985], we use the third-market model of international trade under oligopolistic competition. The description of the model is as follows. We analyse the market for a homogeneous good that is produced by two firms, each located in a different country, i.e., country 1 and country 2 , with constant return to scale functions denoted by $c_{i}\left(x_{i}\right)=c_{i} x_{i}, i=1,2$, where 
$x_{i}$ is the output of firm $i$. Let $p\left(x_{1}+x_{2}\right)$ be the inverse demand function, where $x_{1}$ is the output of firm (country) 1 and $x_{2}$ is the output of firm (country) 2 and let $x=x_{1}+x_{2}$, be the total output, $s_{i}$ the subsidy per unit of output received by firm $i$ and the profit of firm $i$ be given by:

$$
\prod_{i}\left(x_{i}, x, s_{i}\right)=p\left(x_{1}+x_{2}\right) x_{i}-c_{i} x_{i}+s_{i} x_{i}
$$

Without loss of generality, we assume that, in general, the firm's costs in country 1 are lower than those of the firm in country 2 . Each country chooses a subsidy for the firm with the objective of increasing its welfare net of subsidy.

Assumption 1: $U_{i}(\cdot) \in \varepsilon^{2} \quad \forall i \in\{1,2\}$.

Assumption 2: Marginal payoff functions are strictly decreasing in $x$ and in $x_{i} \quad \forall_{i} \in\{1,2\}$.

We consider a two-stage game where firms play a Cournot-Nash game regarding output levels. The firms move into the second stage after the governments have announced their subsidy level in the first one. We assume that both producing countries intervene, that is, both countries choose an export subsidy in order to maximize the social welfare in a non-cooperative setting. ${ }^{3}$ Since there is no domestic consumption, we consider the profits of the firm net of subsidies as the social welfare of each of the two producing countries.

With a subsidy, $s_{i}, i=1,2$, provided by the government (the optimal subsidy has been predetermined in stage 1 and is therefore treated as exogenous), the firm's first-order condition is:

$$
p(x)+p^{\prime}(x) x_{i}-c_{i}+s_{i}=0
$$

By totally differentiating the first-order conditions of profit maximization for both firms we obtain:

$$
\frac{d x_{i}}{d s_{i}}=-\frac{p^{\prime}(x)\left(1+\alpha_{i} R\right) \frac{d x_{j}}{d s_{i}}+1}{p^{\prime}(x)\left[2+\alpha_{i} R\right]} \quad \forall_{i} \in\{1,2\}
$$

where $\alpha_{i}$ is the market share of firm $i,\left[\alpha_{i}=x_{i} / x\right], R$ is a measure of the concavity of demand defined as $R=p^{\prime \prime}(x) x / p^{\prime}(x)$, where $-2+R \geq 0$ from stability conditions, and

$$
\frac{d x_{j}}{d s_{i}}=-\frac{\left(1+\alpha_{j}\right) \frac{d x_{i}}{d s_{i}}}{2+\alpha_{j} R}
$$

Solving the above two expression we obtain:

\footnotetext{
3 As has been pointed out by Brander and Spencer [1985] the subsidy increases domestic welfare net of the subsidy so each country has a unilateral incentive to offer an export subsidy to its firm.
} 


$$
\frac{d x_{i}}{d s_{i}}=-\frac{2+\alpha_{j} R}{p^{\prime}(x)[3+R]}>0
$$

and

$$
\frac{d x_{j}}{d s_{i}}=-\frac{1+\alpha_{j} R}{p^{\prime}(x)[3+R]}<0
$$

On the other hand, we have that:

$$
\frac{d x_{i}}{d x_{j}}=\frac{d x_{i}}{d s_{i}} / \frac{d x_{j}}{d s_{i}}=-\frac{1+\alpha_{i} R}{2+\alpha_{i} R}<0
$$

where $1>\frac{1+\alpha_{i} R}{2+\alpha_{i} R}>0$. It seems to be clear that the introduction of an export subsidy given to firm 1 causes the output to firm 1 to rise and the output of firm 2 to fall. This is due to the fact that an export subsidy is equivalent to a reduction in the production cost, and then, it makes the firm increase production for a given production of the other firm. From that we also obtain that total production rises, price falls, profits of the subsidized firm rise and profits of the rival firm fall.

Once we have solved stage 2 of the game, we turn off to solve stage 1 . In this stage the government chooses an output subsidy in order to maximize social welfare. Since there is no consumption in the producing countries, the social welfare is defined as the home firm's profit net of the value of the subsidy payments. The problem for country 1 can then be defined as:

$$
\max _{\left\{s_{1}\right\}} U_{1}=\prod_{1}\left(x_{1}\left(s_{1}, s_{2}\right), x_{2}\left(s_{1}, s_{2}\right), s_{1}\right)-s_{1} x_{1}\left(s_{1}, s_{2}\right)
$$

The first-order condition is:

$$
\frac{d U_{1}}{d s_{1}}=\frac{\partial \prod_{1}}{\partial x_{1}} \frac{d x_{1}}{d s_{1}}+\frac{\partial \prod_{1}}{\partial x_{2}} \frac{d x_{2}}{d s_{1}}+\frac{\partial \prod_{1}}{\partial s_{1}}-x_{1}-s_{1} \frac{d x_{1}}{d s_{1}}=0
$$

Since $\partial \prod_{1} / \partial x_{1}=0$, and that $\partial \prod_{1} / \partial s_{1}=x_{1}$, the above expression is reduced to:

$$
\frac{\partial \prod_{1}}{\partial x_{2}} \frac{d x_{2}}{d s_{1}}-s_{1} \frac{d x_{1}}{d s_{1}}=0
$$

Therefore, the optimal subsidy level for firm (country) 1 is,

$$
s_{1}=\frac{\partial \prod_{1}}{\partial x_{2}} \frac{d x_{2}}{d x_{1}}
$$

Substituting expression (7) in (11) and taking into account that $\partial \prod_{1} / \partial x_{2}=x_{1} p^{\prime}(x)$, we obtain the same results given by Neary [1994]. The optimal subsidy level for firm 1 is:

$$
s_{1}=\varepsilon p(x) \alpha_{1}\left(\frac{1+\alpha_{2} R}{2+\alpha_{2} R}\right)
$$


where $\varepsilon=-p(x)^{\prime} x / p(x)$ is the elasticity of the demand function. Given symmetry, the optimal subsidy for firm 2 is:

$$
s_{2}=\varepsilon p(x) \alpha_{2}\left(\frac{1+\alpha_{1} R}{2+\alpha_{1} R}\right)
$$

The optimal subsidy is an increasing function of the market share of each firm. This means that the optimal subsidy is increasing in the relative cost advantage of the firm. As Brander [1995] pointed out, firms that need help to compete with foreign rivals are the least attractive targets for strategic assistance from a welfare-maximizing government's point of view.

With symmetric costs, since $\alpha_{1}=\alpha_{2}=1 / 2$, the subsidy is the same for both firms and it is given by

$$
s_{1}=s_{2}=\varepsilon p(x)\left(\frac{2+R}{4+R}\right)
$$

As we can observe, in this case the subsidy is positive for any stable value of the curvature of the demand function $(R>-2)$. However, in the case of asymmetries in cost the subsidy of the higher cost firm can be negative (a tax) if the demand is convex enough. If firm 2 is the higher cost firm, expression (13) is negative if $\alpha_{1} R<1$.

Combining (12) and (13), the difference between both subsidies is:

$$
s_{1}-s_{2}=\varepsilon p(x) \frac{2 \alpha_{1}-2 \alpha_{2}+R\left(\alpha_{1}^{2}+\alpha_{2}^{2}\right)+R^{2}\left(\alpha_{1}^{2} \alpha_{2}-\alpha_{1} \alpha_{2}^{2}\right)}{4+2 R+\alpha_{1} \alpha_{2} R^{2}}
$$

depending on the market share of each firm and on $R$. If firm 1 is the low cost firm, the above difference is positive. Therefore, we obtain the traditional results given by Brander and Spencer [1985], De Meza [1986] and Neary [1994]: the low cost firm obtains the higher subsidy. When the demand function is linear the subsidy differential equals the cost differential. If the demand is non linear the subsidy differential increases.

As it is shown by Brander and Spencer [1985], under symmetry, the game has the general form of a prisoner's dilemma, as both producing countries are worse off than under free trade, but each country has a unilateral incentive to intervene. Collie [1993] uses a linear version of the model to prove that only with significant cost differences it is possible that the more efficient country will be better off at the Nash equilibrium in export subsidies than under free trade. Obviously, this trade policy increases the welfare of country $3 .^{4}$

\footnotetext{
${ }^{4}$ As Brander and Spencer [1985] state, if countries 1 and 2 wish to subsidize country 3 to consume the goods they produce, so much the better for country 3 .
} 


\section{Economic Union}

Next we call into question the case of an economic union of both producing countries plus the third importing country, so now the whole production of the two firms is consumed inside the economic union. We assume that the new economy has a common central authority that chooses the same subsidy levels for both countries. This introduces an important difference as regards to the traditional case considered in the literature. In fact, if each country chooses the subsidy level in a non-cooperative way, in the case of asymmetric costs, the optimal subsidy for each firm is different. In our case, in spite of asymmetry in costs, we assume that the subsidy level for the two firms is the same. ${ }^{5}$ Therefore, the motive for subsidising in this model is not to raise home profits at the expense of foreign competitors, but to maximize total welfare in the union. Obviously, in this case the production subsidy cannot be considered as an export subsidy.

Economic Union with equal subsidies: In the economic union case, we assume that the planner chooses the same level of subsidies for both firms, independently of the cost levels for each firm with the objective of maximizing the total social welfare of both the producers and the consumers net of subsidies. This way, the welfare function depends on the two firms' profits and on consumption in the union, where $U_{3}(x)=V(x)-p x$ is the utility function of consumers (country 3 ). Therefore, the total social welfare of the union can be defined as:

$$
U^{U}\left(s^{U}\right)=\prod_{1}\left(x_{1}, x, s^{U}\right)+\prod_{2}\left(x_{2}, x, s^{U}\right)+U_{3}\left(x, s^{U}\right)-s^{U} x
$$

Substituting, the problem to be maximized is:

$$
\max _{\left\{s_{1}, s_{2}\right\}} U^{U}\left(s^{U}\right)=V(x)-c_{1} x_{1}-c_{2} x_{2}
$$

subject to $s_{1}=s_{2}=s^{U} ; x_{1}, x_{2} \geq 0$. Taking the derivative of (17) yields:

$$
\frac{d U^{U}}{d s^{U}}=\frac{\partial V}{\partial x} \frac{d x}{d s^{U}}-c_{1} \frac{d x_{1}}{d s^{U}}-c_{2} \frac{d x_{2}}{d s^{U}}
$$

Setting the first-order condition equal to zero we obtain:

$$
\left(p-c_{1}\right) \frac{d x_{1}}{d s^{U}}+\left(p-c_{2}\right) \frac{d x_{2}}{d s^{U}}=0
$$

From expression (5) and (6) we obtain that the change in output is:

\footnotetext{
${ }^{5}$ This assumption is based on the fact that it is difficult to justify different output subsidies for each country in the context of an economic union.
} 


$$
\frac{d x_{i}}{d s^{U}}=\frac{d x_{i}}{d s_{1}^{U}}+\frac{d x_{i}}{d s_{2}^{U}}=-\frac{2+\alpha_{j} R}{p^{\prime}(x)[3+R]}+\frac{1+\alpha_{i} R}{p^{\prime}(x)[3+R]}=\frac{\left(\alpha_{i}-\alpha_{j}\right) R-1}{p^{\prime}(x)[3+R]}
$$

The first term, which is positive, measures the effect of the subsidy on the output of the firm; the output subsidy shifts out the best-response function of the firm lowering its effective cost and increasing production. By contrast, the second term is negative, which indicates the loss in output caused by the output subsidy received by the rival firm as also its best-response function shifts out. Note that the change in output depends on the market share of each firm in the case of non-linear demand functions. In the case of convex demand $(R<0)$, output of the lower cost firm (firm 1) increases, whereas output of the higher cost firm (firm 2) decreases if $R\left(\alpha_{2}-\alpha_{1}\right)>1$. For concave demand $(R>0)$ output of the higher cost firm (firm 2) increases whereas output of the lower cot firm (firm 1) decreases if $R\left(\alpha_{1}-\alpha_{2}\right)>1$. Finally, in the case of linear demand $(R=0)$, given that $p^{\prime}(x)=-1$, we have:

$$
\frac{d x_{i}}{d s^{U}}=\frac{1}{3}
$$

that is, the output of the two firms increases by the same amount. On the other hand, the change in total output in the economic union is always positive, independently on the existence of cost asymmetry:

$$
\frac{d x}{d s^{U}}=-\frac{2}{p^{\prime}(x)[3+R]}>0
$$

Substituting expression (20) in the first-order conditions of the firms' profit maximization, yields:

$$
\left(-p^{\prime} x_{1}-s^{U}\right)\left[\frac{\left(\alpha_{i}-\alpha_{j}\right) R-1}{p^{\prime}(x)[3+R]}\right]+\left(-p^{\prime} x_{2}-s^{U}\right)\left[\frac{\left(\alpha_{j}-\alpha_{i}\right) R-1}{p^{\prime}(x)[3+R]}\right]=0
$$

From this we obtain the following expression for the optimal level of the uniform subsidy:

$$
s^{U}=\varepsilon p(x)\left[\frac{1-\left(\alpha_{1}-\alpha_{2}\right)^{2} R}{2}\right]
$$

where $x$ is the total output in the union. ${ }^{6}$ From that, we obtain we following result:

Proposition 1: The uniform output subsidy in the economic union is positive if $R\left(\alpha_{1}-\alpha_{2}\right)^{2}<1$. Otherwise, it is negative (a tax).

\footnotetext{
${ }^{6}$ Only when it is necessary to distinguish between the non-cooperative case and the economic union case we will use the superscript $U$ to denote the output in the economic union situation.
} 
As can be observed, the uniform output subsidy in the economic union, expression (24), is positive for convex and linear demands $(-2<R \leq 0)$. However, if the demand is concave enough and firms have different costs, expression (24) can be negative, indicating the optimal policy is to set up a tax. This is found to be $R\left(\alpha_{1}-\alpha_{2}\right)^{2}>1$. For the linear case, the optimal subsidy in the economic union is:

$$
s^{U}=\frac{\varepsilon p(x)}{2}
$$

Note also that the general expression for the optimal subsidy is the same in the case of symmetry in costs, given that $\alpha_{1}=\alpha_{2}$. Therefore, the expression for the optimal subsidy in the economic union is always positive provided that there is symmetry in production costs. As asymmetries in costs increase, the optimal subsidy becomes negative for concave inverse demand functions. Note that if only the two producing countries join the economic union, then this is in fact an international monopoly regarding the imperfectly competitive product, so the planner's optimal policy is to set up a tax. ${ }^{7}$

From the optimal subsidy level in the economic union we obtain the following well-known result:

Proposition 2: If $c_{1}=c_{2}$, then the price and the output in the economic union are the competitive ones for all $R$. If $c_{1} \neq c_{2}$, then the price is the average of the costs.

Proof: In the case of symmetric costs the market share of both firms is equal and then the optimal subsidy in the economic union is:

$$
s^{U}=\varepsilon p(x) \frac{1}{2}=-p^{\prime}(x) x_{i}
$$

where from the first-order condition of the profit maximization:

$$
-p^{\prime}(x) x_{i}=p(x)-c_{i}+s^{U}
$$

By substitution, we obtain that $p(x)=c_{i}$.

This result implies that, in spite of the fact that we are considering an imperfectly competitive market (a duopoly), the optimal subsidy setting in the economic union motivates the firm to produce the output of a perfectly competitive market, independently of the demand function curvature.

\footnotetext{
${ }^{7}$ In fact, as is pointed out by Neary [1994], if markets are competitive, export subsidies should be zero in a small open economy and should be negative (a tax) if the economy has monopoly power in trade.
} 
Also, if we consider the existence of asymmetric costs, in the case of a linear demand, we obtain the result that the price in the economic union is the average of the costs. The sum of the first-order conditions for the two firms is:

$$
-p^{\prime}(x) x=2 p(x)-c_{1}-c_{2}+2 s^{U}
$$

From expression (25) the uniform output subsidy in the economic union can be defined as:

$$
s^{U}=\frac{-p^{\prime}(x) x}{2}
$$

Substituting (29) in (28) we obtain that:

$$
p(x)=\frac{c_{1}+c_{2}}{2}
$$

Economic Union versus Pre-union export subsidies: In this section, we turn to compare the economic union situation with respect to the traditional solution of two exporting countries setting subsidies in a non-cooperative game. As we have showed above, in the pre-union case, the firm with lower costs obtains the highest subsidy. However, in the economic union, the subsidy level is the same for both firms, independently of costs. If we compare both situations for the cost symmetric case, we obtain the following result.

Proposition 3: In the symmetric case $\left(c_{1}=c_{2}\right)$, the optimal subsidy in the economic union is larger than the optimal subsidy in the non-cooperative game for all $R$.

Proof: By proposition 2 we know that the price in the economic union is the perfectly competitive price, so $p\left(x^{U}\right)=c_{i}$. In the non-cooperative game, given symmetry in costs, the subsidy level for both firms is:

$$
s_{i}=-p^{\prime}(x) x_{i}\left[\frac{2+R}{4+R}\right]
$$

and substituting in the firm's first-order condition, we obtain:

$$
-p^{\prime}(x) x_{i}=p-c_{i}+s_{i}
$$

Using equations (31) and (32) we find that the price in the non-cooperative game is:

$$
p=c_{i}+\frac{2}{2+R} s_{i}
$$

Given that the last term of this expression is positive for $R>-2$, we obtain: 


$$
p\left(x^{U}\right)<p(x)
$$

As the price in the economic union is lower than the price of the product in the noncooperative game, the total output in the economic union is greater. This is only possible if the optimal subsidy level in the economic union is larger than in the pre-union case.

Therefore, we obtain that, with equal production costs, the level of subsidy in the economic union is larger than in the previous situation for all demand functions. This means that production will be larger in the economic union with respect to the previous situation as it is shown by proposition 3. This large level of subsidy is, in fact, caused by the existence of consumers in the social welfare of the union. This way the subsidies are not increasing the consumption (and thus, the social welfare) in a foreign market, but in the domestic market.

A special case in which we can compare the level of subsidies in both situations with asymmetric costs is that in which the demand is linear.

Proposition 4: If $R=0$, the subsidy level in the economic union is greater than in the pre-union case, that is, $s^{U}>s_{1}>s_{2}$.

Proof: Using the first-order condition of the profit maximization problem of firm 1 in the pre-union case, we find that the price is:

$$
p(x)=s_{1}+c_{1}
$$

and similarly for firm 2 . Then, in the pre-union case $c_{2}-c_{1}=s_{1}-s_{2}$. On the other hand, the price in the economic union is:

$$
p\left(x^{U}\right)=\frac{c_{1}+c_{2}}{2}
$$

Therefore, we find that $p\left(x^{U}\right)<p(x)$, given that $\left(c_{1}+c_{2}\right) / 2<c_{1}+s_{1}$. This implies that, at the subsidies level, $x^{U}>x$. This is only possible if $s^{U}>s_{1}>s_{2}$.

In the linear demand case, and in spite of asymmetries in production costs, the level of subsidy in the union is larger than in the previous situation. Then, both firms get a higher level of subsidies. However, the increase in the subsidy that each firm receives is different compared to the previous non-cooperative situation. The less efficient firm receives proportionally more subsidy in the economic union than the most efficient firm. This means that the new policy subsidy shifts out the reaction function of firm 2 by more than the reaction function of firm 1. This implies an allocative change in efficiency regarding the previous situation of non-cooperative export subsidies 
avoiding the effect that a non-cooperative export subsidy helps the winners, given that the level of subsidy of the most efficient firm is larger than the subsidy of the less efficient firm. ${ }^{8}$

Unfortunately, the above proposition cannot be generalized to the case of a non-linear demand. However, given continuity in the level of subsidy respecting the curvature of the demand function, we can approximate the relationship between the subsidies in both situations. From expression (13) we know that the subsidy for the less efficient firm in the pre-union case can be negative if $R<-1 / \alpha_{1}$, that is, for values of the curvature of the demand function between -1 and -2 , depending on the differences in cost. On the other hand, the subsidy for the more efficient firm in the pre-union case is always positive, and following Neary [1994] we know that the minimum difference between both subsidies takes place when the demand is linear. With respect to the subsidy in the economic union, we obtain that it can be negative (a tax) if the demand is concave when there are differences in cost. Finally, the uniform subsidy level is larger than the subsidies in the non-union case when the demand is linear.

Therefore, the optimal subsidy in the economic union is a decreasing function in $R$. In fact, this is due to the presence of the consumer in the government's welfare function. In imperfectly competitive markets, convex demands tend to give high values of the optimal subsidy because the gains in consumer surplus from the lower prices are large relative to the subsidy cost. However, in the case of concave demands, the gains in consumer surplus from lower prices are small relative to the subsidy cost. That is why in the economic union, if the demand is concave enough, the optimal subsidy will be negative. The same argument can be used in the export subsidies pre-union case. As in this case the consumer surplus is not a component of the social welfare of each producing country (all production is for export), they only take into account the profit-shifting effect of the subsidy on the firms. Such effect will be larger in the case of concave demand and smaller in the case of convex demand.

From the previous analysis, we can compare the two situations for some special cases. First, we study the situation in which the optimal level of subsidy in the economic union is equal to the level of subsidy of the most efficient firm in the non-cooperative game. In this case, the uniform subsidy level in the economic union equals the subsidy of firm 1 in the pre-union case and therefore greater than the subsidy of firm $2, s^{U}=s_{1}$ and $s^{U}>s_{2}$. That is, the new subsidy lowers marginal costs to firm 2, but does not change marginal costs to firm 1 . Thus, the new subsidy policy only shifts out the reaction function of firm 2 with respect to the previous situation. This implies that the

\footnotetext{
${ }^{8}$ In the appendix, we present the linear version of the model.
} 
production of this firm will increase and the production of firm 1 will decrease. However, the total production will be increased.

Proposition 5: A level of subsidies in the economic union equals the pre-union subsidy of the lower-cost firm:

(i) Increases the production of the firm with higher costs.

(ii) Decreases the production of the firm with lower costs.

(iii) Increases the total production.

(iv) Increases the profits of the firm with higher costs.

(v) Decreases the profits of the firm with lower costs.

Proof:

i) Increases the production of the firm with higher costs:

The first-order condition of the maximization problem of firm 2 is:

$$
p(x)+p^{\prime}(x) x_{2}-c_{2}+s^{U}=0
$$

Differentiating (37) with respect to $x_{2}$ and $s^{U}$ :

$$
\frac{d x_{2}}{d s^{U}}=-\frac{2+\alpha_{1} R}{p^{\prime}(x)[3+R]}>0
$$

ii) Decreases the production of the firm with lower costs:

The first-order condition of the maximization problem of firm 1 is:

$$
p(x)+p^{\prime}(x) x_{1}-c_{1}+s^{U}=0
$$

Differentiating (39) with respect to $x_{1}$ and $x_{2}$ :

$$
\frac{d x_{1}}{d x_{2}}=-\frac{1+\alpha_{1} R}{2+\alpha_{1} R}<0
$$

iii) Increases the total production:

$$
\frac{d x}{d s^{U}}=\frac{d x_{2}}{d s^{U}}+\frac{d x_{1}}{d x_{2}} \frac{d x_{2}}{d s^{U}}=\frac{d x_{2}}{d s^{U}}\left[1+\frac{d x_{1}}{d x_{2}}\right]=-\frac{1}{p^{\prime}(x)[3+R]}>0
$$

given that $-1<\frac{d x_{1}}{d x_{2}}<0$.

iv) Increases the profit of the firm with higher costs:

$$
\frac{d \prod_{2}}{d s^{U}}=\frac{\partial \prod_{2}}{\partial x_{1}} \frac{d x_{1}}{d s^{U}}+\frac{\partial \prod_{2}}{\partial x_{2}} \frac{d x_{2}}{d s^{U}}+\frac{\partial \prod_{2}}{\partial s^{U}}=\frac{\partial \prod_{2}}{\partial x_{1}} \frac{d x_{1}}{d s^{U}}+x_{2}=x_{2}\left[1+\frac{1+\alpha_{2} R}{3+R}\right]>0
$$

v) Decreases the profit of the firm with lower costs: 


$$
\frac{d \prod_{1}}{d s^{U}}=\frac{\partial \prod_{1}}{\partial x_{1}} \frac{d x_{1}}{d s^{U}}+\frac{\partial \prod_{1}}{\partial x_{2}} \frac{d x_{2}}{d s^{U}}=\frac{\partial \prod_{1}}{\partial x_{2}} \frac{d x_{2}}{d s^{U}}=-\frac{x_{1}\left[2+\alpha_{1} R\right]}{3+R}<0
$$

This way we obtain the result that profits in country 1 (the cost-efficient country) decrease, whereas profits in country 2 (the highest cost country) increase.

Second, we study the situation in which the uniform output subsidy in the economic union is equal to the level of subsidy of the less efficient firm in the non-cooperative game (pre-union). In this case, the uniform subsidy level is equal to the subsidy of firm 2 in the pre-union case and therefore lower than the subsidy of firm 1 . That is, the new subsidy does not affect the marginal costs of firm 2, but it increases the marginal costs of firm 1, given that the level of subsidy in this situation is lower. So, $s^{U}<s_{1}$ and $s^{U}=s_{2}$. Thus, the new subsidy policy only shifts to the left the reaction function of firm 1 with respect to the previous situation. This implies that the production of this firm will decrease while the production of firm 2 will increase. However, in this case we expect a reduction in the total production.

Proposition 6: A level of subsidies in the economic union equals the pre-union subsidy level of the higher-cost firm:

(i) Decreases the production of the firm with lower costs.

(ii) Increases the production of the firm with higher costs.

(iii) Decreases the total production.

(iv) Increases the profits of the firm with higher costs.

(v) Decreases the profits of the firm with lower costs.

Proof:

i) Decreases the production of the firm with lower costs:

Differentiating the first order condition of firm 1 with respect to $x_{1}$ and $s^{U}$ :

$$
\frac{d x_{1}}{d s^{U}}=-\frac{2+\alpha_{2} R}{p^{\prime}(x)[3+R]}>0
$$

since the derivative is positive, a reduction in the subsidy to firm 1 will reduce its production.

ii) Increases the production of the firm with higher costs:

Differentiating the first order condition of firm 2 with respect to $x_{1}$ and $x_{2}$ :

$$
\frac{d x_{2}}{d x_{1}}=-\frac{1+\alpha_{2} R}{2+\alpha_{2} R}<0
$$

given the negative relationship between outputs, the reduction in the output 
of firm 1 causes an increase in the output of firm 2.

iii) Decreases the total production:

$$
\frac{d x}{d s^{U}}=\frac{d x_{1}}{d s^{U}}+\frac{d x_{2}}{d x_{1}} \frac{d x_{1}}{d s^{U}}=\frac{d x_{1}}{d s^{U}}\left[1+\frac{d x_{2}}{d x_{1}}\right]=-\frac{1}{p^{\prime}(x)[3+R]}>0
$$

as the above expression is positive, a reduction in the subsidy to firm 1 will reduce the total production.

iv) Increases the profit of the firm with higher costs:

$$
\frac{d \prod_{2}}{d s^{U}}=\frac{\partial \prod_{2}}{\partial x_{1}} \frac{d x_{1}}{d s^{U}}+\frac{\partial \prod_{2}}{\partial x_{2}} \frac{d x_{2}}{d s^{U}}=\frac{\partial \prod_{2}}{\partial x_{1}} \frac{d x_{1}}{d s^{U}}=-\frac{x_{2}\left[2+\alpha_{2} R\right]}{3+R}<0
$$

as the above expression is negative, a reduction in the subsidy to firm 1, increases profits of firm 2.

v) Decreases the profit of the firm with lower costs

$$
\frac{d \prod_{1}}{d s^{U}}=\frac{\partial \prod_{1}}{\partial x_{1}} \frac{d x_{1}}{d s^{U}}+\frac{\partial \prod_{1}}{\partial x_{2}} \frac{d x_{2}}{d s^{U}}+\frac{\partial \prod_{1}}{\partial s^{U}}=\frac{\partial \prod_{1}}{\partial x_{2}} \frac{d x_{2}}{d s^{U}}+x_{1}=x_{1}\left[1+\frac{1+\alpha_{1} R}{3+R}\right]>0
$$

as the above expression is positive, a reduction in the subsidy to firm 1 decreases profits of firm 1 . Therefore, we obtain the result that profits in country 1 (the cost-efficient country) decrease, whereas profits in country 2 (the less efficient country) increase.

\section{Conclusions}

In this paper we show the importance of cost asymmetry and demand elasticity for subsidy policy in the case of an economic union in the context of the "third-market" model proposed by Brander and Spencer [1985]. We compute the optimal subsidy level in an economic union of the two producing countries and the importing country under the assumption of uniform subsidies for both firms, independently of the existence of asymmetries in costs. We find that the optimal subsidy in the economic union can be negative (a tax) if firms have different costs and the demand is concave. Of course, we obtain this result neglecting cost asymmetry between private and social costs, that is, assuming that the social cost of public funds is unity. Another important question is the amount of the total subsidy that each country has to pay. In this paper we assume that the subsidy is paid by the common economic authority, regardless of the proportion corresponding to each of the three countries. Part of our current research agenda is the introduction of asymmetry between private and social costs in an economic union plus taking into consideration the proportion of the amount of subsidy that each country in the union is able to pay. 
As a result, we find that the output (and hence the price) in the economic union with the optimal subsidy is the perfectly competitive one, independently of the demand curvature. When comparing the economic union case with the non-cooperative strategic policy game, we find that, when costs are symmetric, the optimal uniform output subsidy level in the union is greater than in the non-cooperative case for any curvature of the demand function. We also show that, with asymmetries in costs and a linear demand, the optimal subsidy in the union is larger than the optimal subsidies of the firms in the previous situation.

We study two particular cases, when the uniform output subsidy is equal to the subsidies received by each firm in the pre-union profit-shifting export subsidy situation. We obtain the new subsidy policy in the economic union (uniform output subsidy) favours the less efficient firm compared to the pre-union non-cooperative export subsidy situation.

\section{Appendix}

In this appendix we present a linear version of the model. Let $x=x_{1}+x_{2}$ be the total output and $p(x)=a-x$ be the inverse demand function, with $a>0$. Let $s_{i}$ be the subsidy per unit of output received by firm $i$ and $M_{i}$ be the total amount of money to be paid by country $i$. The profit function of firm $i$ is

$$
\prod_{i}\left(x_{i}, x, s_{i}\right)=\left(a-c_{i}-x\right) x_{i}+s_{i} x_{i}
$$

and given that there is no consumption in the producing countries, the social welfare of country $i$, for $i=1,2$, only depends on firm's profits and the value of subsidy payments, and it is defined as:

$$
U_{i}\left(x_{i}, x, s_{i}\right)=\prod_{i}\left(x_{i}, x, s_{i}\right)-M_{i}
$$

whereas the social welfare of country 3 is:

$$
U_{3}(x)=a x-\frac{x^{2}}{2}-(a-x) x-M_{3}
$$

Without loss of generality, we assume that the firm in country 1 is more efficient than the firm in country 2 , i. e., $c_{1}<c_{2}$. Let $A=a-c_{2}$ and $t A=a-c_{1}$. We assume that $A>0$ and $t \in\left(1, \frac{3}{2}\right)$, where $t$ can be interpreted as a measure of the cost differences between the firms. ${ }^{9}$ Let $U\left(x, s_{i}, s_{j}\right)$ be the total social welfare obtained as the sum of the welfare of the three countries.

\footnotetext{
${ }^{9}$ This assumption is necessary in order to ensure that, in the case of the countries competing in subsidies, the output of the less efficient firm is positive.
} 
We now focus on the relationship between a situation in which countries compete in subsidies with a situation in which the three countries decide to form an economic union with a common economic authority that decides a common level of subsidies for both firms in order to maximize the joint social welfare of the three countries.

Non-cooperative subsidies: We denote the Nash equilibrium variables in this situation with the superscript $n u$ (non-union). The Nash equilibrium subsidies, output and profits subsidies for each firm are

$$
\begin{aligned}
& s_{1}^{n u}=\frac{A(3 t-2)}{5}, s_{2}^{n u}=\frac{A(3-2 t)}{5} \\
& x_{1}^{n u}=\frac{2 A(3 t-2)}{5}, x_{2}^{n u}=\frac{2 A(3-2 t)}{5} \\
& \prod_{1}^{n u}=\frac{4}{25}[A(3 t-2)]^{2}, \prod_{2}^{n u}=\frac{4}{25}[A(3-2 t)]^{2}
\end{aligned}
$$

The noncooperative Nash subsidy equilibrium is characterized by positive production subsidies in both producing countries. However, the more cost competitive firm gets the higher level of subsidy and the subsidy differential equals the production cost differential (see Neary, 1994).

In this situation, each of the producing countries pays the total amount of subsidies to its firm and country 3 pays nothing. Therefore, $M_{i}^{n u}=s_{i}^{n u} x_{i}^{n u}$ for $i=1,2$ and $M_{3}^{n u}=0$. Operating, the total social welfare at the Nash equilibrium for the three countries is

$$
U^{n u}=\frac{4}{25} A^{2}\left(7 t^{2}-11 t+7\right)
$$

As it is shown by Collie [1993], the social welfare of the producing countries will usually be lower at the Nash equilibrium in production subsidies than under free trade. Thus, both countries will usually lose if there is a trade war as Bhagwati [1988] claimed. Only with significant cost differences it is possible that the most efficient country will be better off at the Nash equilibrium in export subsidies than under free trade. Finally, country 3 increases its social welfare given that the subsidies decrease the price and increase the total output.

Economic Union: In the situation in which the three countries decide to form an economic union, we assume the existence of a common economic authority. This common authority decides a common level of subsidies for both firms such that the social welfare of the economic union is maximized. As before, we assume that the decision on the level of subsidy is irreversible and prior 
to the decision of firms on output. We denote the equilibrium variables in this situation with the superscript 123 (the three countries in the economic union). We assume that there is a joint financial responsibility by the countries in the union. The social welfare function in this case is defined as:

$$
U^{123}(s)=\prod_{1}\left(x_{1}, x, s\right)+\prod_{2}\left(x_{2}, x, s\right)+U_{3}(x, s)-M
$$

where $M=\sum_{j=1}^{3} M_{j}$, given the financial responsibility in the union. The Nash equilibrium common subsidy, output and profits of each firm in the economic union are:

$$
\begin{aligned}
& s^{123}=\frac{A(t+1)}{4} \\
& x_{1}^{123}=\frac{A(3 t-1)}{4}, x_{2}^{123}=\frac{A(3-t)}{4} \\
& \prod_{1}^{123}=\frac{1}{16}[A(3 t-1)]^{2}, \prod_{2}^{123}=\frac{1}{16}[A(3-t)]^{2}
\end{aligned}
$$

As we can observe, the optimal subsidy, output and profits of both firms in the economic union of the three countries are larger than the equilibrium values in the non-cooperative export subsidy game $\left(s^{123}>s_{1}^{n u}>s_{2}^{n u}\right)$. Operating, the Nash equilibrium total social welfare for the three countries is

$$
U^{123}=\frac{1}{8} A^{2}\left(5 t^{2}-6 t+5\right)
$$

Comparing the total social welfare in both situations, we obtain that there are values of $t$ $\left(t \in\left[1, \frac{11}{9}\right]\right)$ for which the total social welfare in the economic union is greater than the total social welfare in the pre-union situation. Moreover, the total social welfare in the economic union is always larger than that in the free trade (no subsidies) situation.

\section{References}

Balassa, B. [1961], The Theory of Economic Integration, Homewook, Irwin.

Bandyopadhyay, S. [1997], Demand elasticities, asymmetry and strategic trade policy, Journal of International Economics 42; pp. 167-177.

Bhagwati, J. [1988], Protectionism, MIT Press, Cambridge.

Brander, J. [1995], Strategic trade policy, Handbook of International Economics, vol. III, edited by G. Grossman and K. Rogoff, Elsevier Science BV. 
Brander, J. and Spencer B. [1985]: Export subsidies and international market share rivalry, Journal of International Economics 18; pp. 83-100.

Collie, D. [1993], Profit-shifting export subsidies and the sustainability of free trade, Scottish Journal of Political Economy, 40; pp. 408-419.

De Meza, D. [1986], Export subsidies and high productivity: Cause or Effect? Canadian Journal of Economics 19; pp. 347-350.

Gruenspecht, H. [1988], Export subsidies for differentiated products, Journal of International Economics 24; pp. 331-344.

Hine, R. [1994], International economic integration, in Surveys in International Trade, edited by D. Greenaway y L., Winters, Blackwell.

Neary, J. [1994], Cost asymmetries in international subsidy games: Should governments help winners or losers?, Journal of International Economics 37; pp. 197-218. 